\title{
Acute oliguric renal failure secondary to lymphomatous infiltration of the kidneys
}

\author{
A. C. T. LEUNG \\ M.B.B.S., M.R.C.P. \\ R. MACTIER \\ M.B., Ch.B., M.R.C.P. \\ M. MCKEAN* \\ M.B., Ch.B. \\ J. W. DOBBIE \\ M.D., F.R.C.P., F.R.C.Path.
}

Renal Unit and *Department of Pathology, Glasgow Royal Infirmary, Castle Street, Glasgow G4 OSF

\begin{abstract}
Summary
A case of lymphomatous infiltration of the kidneys presenting as acute oliguric renal failure of unknown cause is described. Renal biopsy was required to establish the diagnosis. Combined chemotherapy (MOPP) produced significant improvement in renal function.
\end{abstract}

KEY WORDS: lymphoma, acute renal failure, renal biopsy, chemotherapy.

\section{Introduction}

Lymphomatous infiltration of the kidney is a wellrecognized finding in post-mortem examination, up to $33.5 \%$ in one large series (Richmond et al., 1962) but clinical involvement of the urinary tract is much less frequent. Uraemia as the main or sole cause of death in lymphoma occurred in only 0.5 to $2 \%$ (Richmond et al., 1962; Ostrow et al., 1981).

Acute renal failure secondary to massive lymphomatous infiltration of the kidneys has rarely been reported (Ellman, Davis and Lichtenstein, 1974; Kanfer et al., 1976). It is important to diagnose this condition since treatment with chemotherapy and/or local radiotherapy has been shown to be effective (Kanfer et al., 1976; Ellman et al., 1974). We describe here such a case where the diagnosis was established on renal biopsy and significant improvement in renal function occurred on combined chemotherapy.

\section{Case report}

A 77 -year-old man presented in January 1983 with acute oliguric renal failure. He had a 9-month history of epigastric discomfort with intermittent nausea and vomiting. He was anorexic, lethargic and had lost about one stone of weight. There was no gastrointestinal bleeding or significant urinary symptoms.

Correspondence: Dr A. C. T. Leung.
Serum urea and creatinine were $10.2 \mathrm{mmol} / 1$ and 165 $\mu \mathrm{mol} / 1$ respectively 2 months before admission. AO recent barium meal examination and upper gastrou intestinal endoscopy had revealed no significan? pathology. Physical examination showed pallor, no lymphadenopathy, blood pressure $150 / 85 \mathrm{mmHg}_{3}^{-}$ mild congestive cardiac failure and left pleura effusion. A slightly tender epigastric mass, $5 \times 4 \mathrm{~cm}$ ? moving with respiraton, was detected on abdominaf examination but there was no hepatosplenomegaby $\vec{\circ}$ Urinalysis showed + protein, 100 red blood cells pep high power field and a few granular casts.

Investigations showed haemoglobin $10 \mathrm{~g} / \mathrm{dl}$, whit cell $11.3 \times 10^{9} / 1$, and platelet counts $441 \times 10^{9} / 1$ serum urea $43 \mathrm{mmol} / 1$, creatinine $931 \mu \mathrm{mol} / 1$, cal cium $2.0 \mathrm{mmol} / 1$, phosphate $2.95 \mathrm{mmol} / 1$, urate 6060 $\mu \mathrm{mol} / 1$, albumin $29 \mathrm{~g} / 1$, globulin $20 \mathrm{~g} / 1$, plasma and urine protein electrophoresis showed diffuse decrease of alpha-one and gammaglobulins. Urine and blood cultures were negative. Chest X-ray confirmed of moderate left pleural effusion, mild cardiomegaly but no mediastinal lymph node enlargement. Retrogrades urogram showed no calculi and a normal left: pelvicalyceal system (the right side was not catheter ized). Ultrasound examination showed normal sized kidneys (right $12 \mathrm{~cm}$, left $11 \mathrm{~cm}$ ) with smooth outline and slight dilatation of the right pelvi-calyceab system. A central epigastric mass $4 \times 6 \times 5 \mathrm{~cm}$ was detected, probably arising from the gastric antrumo Pleural fluid and peritoneal fluid cytology revealeot the presence of lymphomatous cells.

A percutaneous left renal biopsy was undertakeñ and this showed extensive infiltration of the renaR parenchyma by lymphomatous cells (Figs. 1, 2). Both lymphocytic and histiocytic elements were present but definite classification is not possible. The glomer uli were relatively normal and amyloid deposit was? not detected.

The patient received two short courses of perito $\frac{0}{0}$ neal dialysis and later haemodialysis. After histologi 


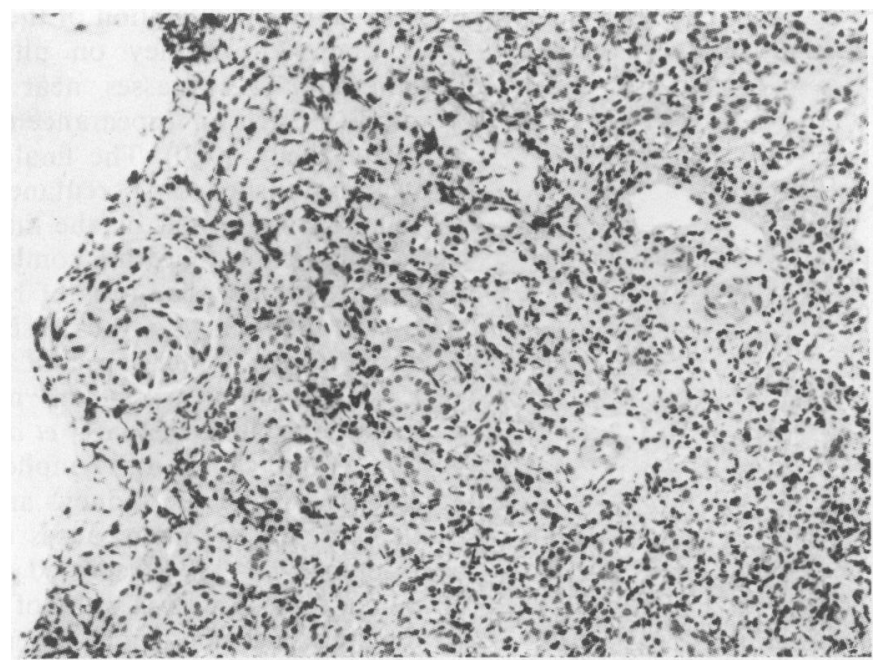

FIG. 1. Renal biopsy. Low power shows a normal glomerulus and an interstitial infiltrate $(\mathrm{H} \& \mathrm{E}, \times 153)$.

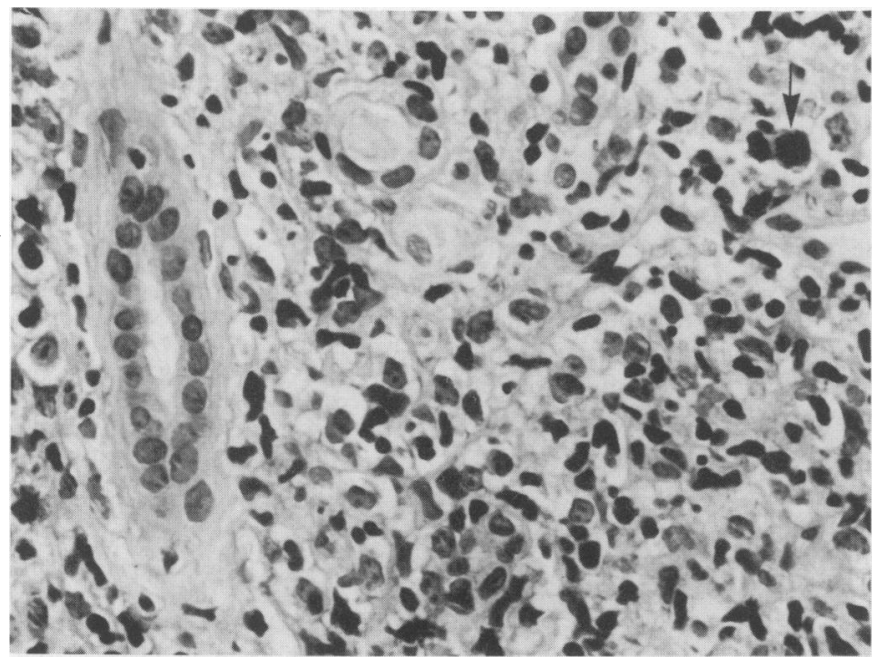

FIG. 2. Renal biopsy. High power shows an infiltrate of pleomorphic small cells of probable lymphoid origin. A mitotic figure is arrowed (H \& E, $\times$ 540).

cal diagnosis had been obtained on the renal biopsy combined chemotherapy with the MOPP regime (intravenous mustine and vinblastine and oral procarbazine and prednisolone) was commenced. This was followed by increase in urine output, improvement of renal function and regression of the left pleural effusion and epigastric mass (see Fig. 3). Pancytopenia was noted a week later and chemotherapy was stopped. However, the patient developed massive gastro-intestinal bleeding and later succumbed to an aspiration pneumonia.

\section{Discussion}

Lymphoma can lead to renal failure in a number of ways. Bilateral ureteric obstruction, venocaval compression, hypercalcaemia, uric acid nephropathy, amyloidosis and immunologically mediated nephritis have all been described (Kiely, Wagner and Holley, 1989; Belghiti et al., 1981). Lymphomatous infiltration of the kidneys is common at autopsy but the kidneys can be massively infiltrated by lymphomatous cells and still have relatively normal function. Acute renal failure secondary to lymphomatous 


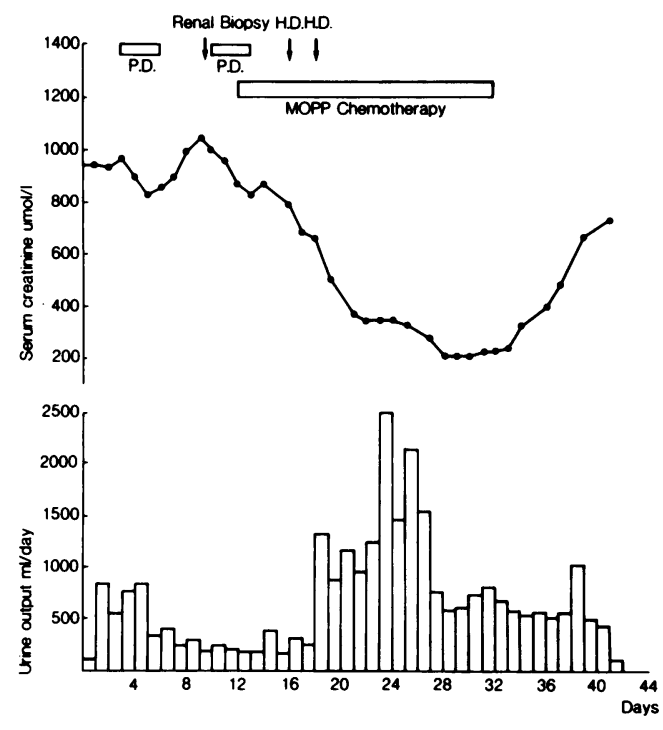

FiG. 3. Acute oliguric renal failure secondary to lymphomatous infiltration of the kidneys - response to combined chemotherapy. $\mathrm{PD}=$ peritoneal dialysis. $\mathrm{HD}=$ haemodialysis .

infiltration of the kidneys is extremely uncommon (Knoepp, 1956; Ellman et al., 1974; Kanfer et al., 1976).

The cause of acute renal failure in our patient must be largely if not exclusively due to lymphomatous infiltration of the kidneys. The relatively normal serum creatinine 2 months before admission precluded significant chronic renal insufficiency. Normal serum calcium and plasma and urine protein electrophoresis made nephrocalcinosis and 'myeloma' kidney unlikely. Serum urate was moderately elevated at $600 \mu \mathrm{mol} / 1$ initially but fell to $430 \mu \mathrm{mol} / 1$ 2 days after admission. The patient was never dehydrated and crystalluria was not observed. Acute uric acid nephropathy complicating lymphoma usually occurs after the start of chemotherapy and is associated with a much higher serum urate level. The patient had no loin tenderness or gross haematuria to suggest venocaval obstruction or renal vein thrombosis. The minimal proteinuria and normal kidney size also make this unlikely. Renal amyloidosis was excluded by the lack of amyloid deposit on the renal biopsy. Bilateral ureteric obstruction was unlikely in view of the normal kidney size, and normal retrograde urogram of the left kidney. Although there may be slight dilatation of the pelvi-calyceal system of the right kidney on ultrasound examinatiog, lymphomatous masses near the renal sinus can produce such an appearance (Shirkhoda, Staab and Mittelstaedt, 1980). The final diagnosis in our casse was established on percutaneous renal biopsy ard this was confirmed by the marked improvement renal function following combined chemotherapy. $\frac{\omega}{\frac{\omega}{n}}$

Antemortem diagnosis of lymphomatous infiltr $\$$ tion of the kidneys as the cause of renal failure can ge very difficult. Other causes of acute renal failure such as dehydration, sepsis and metabolic disturbances must be excluded. Kanfer et al. (1976) reported that this complication of lymphoma is suggested enlargement of the kidneys and mild proteinuria the absence of other causes of uraemia. Howeve Ellman et al. (1974) reported a case where, as in ogr patient, the kidneys were of normal size and the diagnosis was made only by renal biopsy. Good gres scale ultrasound examination and gallium isoto scanning may be helpful especially when used together (Shirkhoda et al., 1980). The final histological diagnosis, however, often relies on open or closed needle biopsy of the kidney (Ellman, et al., 197 Kanfer $e$ al., 1978). It is important to recognize thes uncommon complication of lymphoma since chem\& therapy and/or radiotherapy can produce gratif\&ieg improvement in renal function.

\section{References}

Belghiti, D., Vernant, J.O., Hirbec, G., Gubler, M., ANDre, $\overline{\bar{g}}$ \& SOBEL, A. (1981) Nephrotic syndrome associated with $t$-ब्बl lymphoma. Cancer, 47, 1878.

Ellman, L., Davis, J. \& Lichtenstein, N.S. (1974) Uraemia due to occult infiltration of the kidney. Cancer, 33, 203.

KANFER, A., VANDERVAlle, A., MORel-Maroger, K., Feintuç M.J., GRAER, J.D. \& ROLAND, J. (1976) Acute renal insufficiency due to lymphomatous infiltration of the kidney. Cancer, 38, 2588.

KIELY, J.M., WAGNER, R.D. \& Holley, K.E. (1969) Rengi complications of lymphoma. Annals of Internal Medicine, 71, 11 9.

KNOEPP, L.F. (1956) Lymphosarcoma of the kidney. Surgery, 39 , 510.

Ostrow, S., Diggs, C.H., Sutherland, J. \& WierniK, P.H. (19\$.) Causes of death in patients with non-Hodgkin's lymphorga. Cancer, 48, 779.

Richmond, J., Sherman, R.S., Diamond, H.D. \& Craven, L.F. (1962) Renal lesions associated with malignant lymphom American Journal of Medicine, 32, 184.

ShiRKhoda, A., StAaB, E. \& MitTelstaedt, C.A. (1980) Re lymphoma imaged by ultrasound and gallium-67. Radiology, 137, 175.

(Accepted 7 July 1983) 